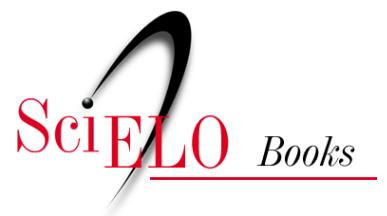

EDUFU

\title{
O professor no processo de constituição do aluno pela escrita acadêmica
}

\author{
Ernesto S. Bertoldo
}

\section{SciELO Books / SciELO Livros / SciELO Libros}

BERTOLDO, E.S. O professor no processo de constituição do aluno pela escrita acadêmica. In: AGUSTINI, C., and ERNESTO, B., eds. Incursões na escrita acadêmico-universitária: letramento, discurso, enunciação [online]. Uberlândia: EDUFU, 2017, pp. 107-120. ISBN: 978-65-86084-26-9. https://doi.org/10.7476/9786586084269.0007.

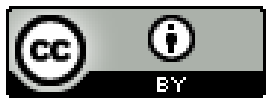

All the contents of this work, except where otherwise noted, is licensed under a Creative Commons Attribution 4.0 International license.

Todo o conteúdo deste trabalho, exceto quando houver ressalva, é publicado sob a licença Creative Commons Atribição 4.0. 


\title{
O professor no processo de constituição do aluno pela escrita acadêmica
}

\author{
Ernesto S. Bertoldo
}

A entrada na ordem do discursivo-acadêmico ${ }^{1}$ parece constituir um desafio para os futuros professores de língua materna e estrangeira em formação nos cursos de licenciatura em letras. Tal desafio nos remete diretamente às questões sobre escrita e leitura, demandadas a alunos em seus processos de formação como professores de língua portuguesa e de línguas estrangeiras.

De modo geral, é possível dizer que o letramento acadêmico não encerra simplesmente "dominar" técnicas de escrita e de leitura, tendo em vista sua execução, reprodução ou mesmo "aplicação" na sala de aula. Para além disso, o letramento acadêmico pode ser trabalhado com vistas a propiciar aos alunos em formação condições para que os mesmos construam sentido do mundo da linguagem escrita e oral no qual estão imersos. Letrar-se, academicamente, assim, refere-se à constituição dos alunos em práticas discursivas que supõem, por sua vez, práticas acadêmicas letradas. 0 letramento acadêmico demanda, portanto, que os professores em formação se constituam em um conjunto de concepções e de procedimentos nos domínios específicos das instituições educacionais.

\footnotetext{
${ }^{1}$ Neste capítulo, não trabalharemos especificamente com o texto de Foucault (1971). Reconhecemos, no entanto, a partir de outros autores trabalhados, que esse termo advém de sua obra "A ordem do discurso", resultado de uma conferência proferida no Collège de France.
} 
A título de exemplificação, espera-se que aquele, academicamente letrado, seja capaz de ler um artigo sobre um determinado assunto de uma área de conhecimento específico, produzindo, a partir dessa leitura, interpretações coadunadas com as problemáticas tratadas por esse campo específico de conhecimento. 0 sujeito academicamente letrado seria, assim, aquele que, ao enunciar sobre esse ou aquele assunto em uma determinada área do conhecimento, demonstraria estar constituído daquelas práticas discursivas pertinentes aos modos de dizer e, em decorrência, de produzir conhecimento daquela área específica. Essa seria, a nosso ver, uma das condições que possibilitaria ao sujeito não só transitar pelas regras dos modos de dizer do discurso acadêmico, mas também resistir às suas próprias imposições.

Em sendo assim, um professor de línguas, tanto materna quanto estrangeira, será requisitado a responder por questões e /ou demandas que seu objeto de trabalho reclama. Deverá, por exemplo, tomar decisões sobre questões específicas ligadas à escolha ou não de livros didáticos na escola em que trabalha, participar de discussões sobre o conteúdo programático, fazendo reflexões consoantes com opções teóricas pertinentes ao seu campo de atuação, nesse caso específico, aos estudos sobre o ensino e a aprendizagem de línguas. Deverá, ainda, discutir a pertinência dos postulados de documentos oficiais sobre o ensino e a aprendizagem de línguas, dentre outras demandas características de sua atuação profissional que dizem respeito, via de regra, ao ensino de uma determinada língua propriamente dita.

Essa perspectiva do letramento acadêmico, então, como um lugar em que práticas discursivo-acadêmico-letradas são requeridas implica modos de dizer específicos constitutivos do discurso acadêmico; em última instância, são elas que possibilitam que os professores em formação respondam àquilo que advém como demanda de seu objeto de trabalho (o ensino de línguas). É nesse sentido que podemos afirmar que tais respostas extrapolam aquilo que se conseguiria somente pela via do senso comum. Em outras palavras, as respostas às demandas do objeto de trabalho, a serem enfrentadas pelos professores, implicam escolhas teóricas que, para advirem, estariam relacionadas ao fato de que esses professores nelas estariam constituídos, independentemente de qual fosse a opção ou as opções teóricas adotadas.

Ao nos referirmos à teoria, nesse caso, estamos, na verdade, nos remetendo aos saberes específicos necessários ao professor para 
responder a isso que seria da ordem da demanda de seu objeto de trabalho, conforme aludido anteriormente, ou seja, o ensino de línguas.

Julgamos ter, ainda que de forma concisa, descrito alguns aspectos constitutivos da entrada dos professores em formação na ordem do discurso acadêmico. E, em sendo assim, a reflexão de Gee (2012) sobre esse assunto parece-nos relevante para o entendimento do que estamos postulando, aqui, sobre as implicações da entrada na ordem desse discurso. Segundo o autor, no espaço discursivo-acadêmico, ler e escrever intransitivamente, qualquer coisa, é algo que não se cogita. Ler e escrever no espaço discursivo-universitário seria, então, ler e escrever a partir da constituição pela via de dizeres que encerram discursos outros, diferentes daqueles primários que nos constituíram desde a infância no nosso âmbito familiar.

Diante disso, o problema que se apresenta para os alunos, professores em formação, nesse processo de entrada na ordem do discurso acadêmico, refere-se ao fato de que nessa formação não temos a garantia de que a constituição dos alunos nas referidas práticas discursivas acadêmicas letradas e, em consequência, nos modos de dizer do discurso acadêmico, ocorrerá, uma vez que essa constituição implica que os professores em formação estejam em uma relação identitária, ${ }^{2}$ inicialmente, com a língua

${ }^{2}$ Ao falarmos em relação identitária, aqui, mobilizamos o conceito a partir do ponto de vista psicanalítico. De acordo com Nasio (1989, p.101), para Lacan, “[...] o conceito lacaniano de identificação responde a um desafio mais extremo do que o desafio freudiano, já que não se trata mais de dar conta da relação entre dois termos relativamente bem constituídos - um eu determinado identificando-se com um objeto igualmente definido - mas de dar nome a uma relação em que um dos termos cria o outro. [...] a identificação é o nome que serve para designar o nascimento de uma nova instância psíquica, a produção de um novo sujeito. [...] estamos longe do esquema tradicional da identificação compreendida como uma transformação entre dois termos previamente existentes, $A$ transformando-se em $B$, estamos em um esquema muito diferente, o esquema da causação de um desses termos, produzido pelo outro. [...],não apenas a identificação é inconsciente, não apenas significa engendramento, mas ainda e, sobretudo, o sentido do processo é invertido. Em vez de A se transformar em B, [...] é B que produz A. A identificação significa que a coisa com a qual o eu se identifica é a causa do eu. [...] o agente da identificação é o objeto e não mais o eu.". Para efeitos de nossa discussão, tendo em vista o conceito de identificação, aqui exposto, reiteramos que a entrada dos professores em formação na ordem do discurso acadêmico não é algo passível de controle no processo de formação. No entanto, parece-nos que, sem que o professor em formação se deixe captar por esses novos (outros) modos de dizer, sua entrada na ordem do discurso acadêmico pode ficar comprometida, uma vez 
que estudam e, em decorrência, com os assuntos afeitos ao seu ensino. No caso da formação dos professores, tanto de língua portuguesa quanto de língua estrangeira, trata-se de uma tarefa dupla: ao mesmo tempo em que estudam a língua em um processo de aprendizagem da mesma, são impelidos a pensar e se formar, como especialistas, sobre os aspectos teóricos e metodológicos que envolvem o seu ensino.

Nesse sentido, aos professores formadores dos cursos de letras impõe-se uma tarefa desafiadora: proporcionar as condições para que esse processo seja desencadeado para que, a partir dele, seja possível problematizar com os professores em formação o que seria uma relação de implicação com o objeto de trabalho no processo de formação vivenciado em um curso de letras.

Neste capítulo, impusemo-nos a tarefa de elucidar essa discussão a partir da problematização da relação entre um professor de um curso de letras, que ministra a disciplina intitulada "Práticas Discursivas da Academia", e uma aluna em formação. Diante disso, postulamos que um dos aspectos que caracteriza a relação do professor de escrita acadêmica com o professor em formação seria levar em conta que o processo de constituição do aluno em formação em práticas discursivas acadêmicas letradas comporta uma tensão entre as duas partes, o que, a nosso ver, seria a condição para que esse professor em formação nelas se constituísse.

Dizemos isso em função do fato de que a formação intelectual, nesse caso, em nível superior, supõe uma demanda psíquica considerável do aluno em formação. Isso porque, dentre outros aspectos, essa formação implica um contato direto com modos de dizer próprios do discurso acadêmico que colocam esse aluno em contato direto com um estranhamento e uma dificuldade eminentes, dada a história de cada professor em formação de se constituir nesse espaço das práticas discursivas acadêmicas letradas. É com essa realidade que tanto o professor quanto o aluno em formação lidam ao se confrontarem com a tarefa da formação intelectual de um professor de línguas.

Para fins específicos desta discussão, relatamos alguns aspectos que puderam ser notados no percurso de uma aluna em seu processo de formação como professora de língua inglesa em um curso de letras. Enfocaremos os impasses ou as dificuldades vivenciadas pela aluna em formação e pelo professor formador ${ }^{3}$ ao se confrontarem com uma tarefa

que não se torna possível uma relação em que ele seja causado por esses modos de dizer outros.

${ }^{3}$ Esclarecemos que o professor formador coincide com o autor deste capítulo. 
específica relacionada à escrita acadêmica, qual seja, a escrita de uma resenha em língua estrangeira. É preciso dizer que, ao falarmos em impasses, estamos na perspectiva de pensar tanto naqueles da aluna em formação quanto nos do professor formador, uma vez que a tarefa de mobilizar e engajar um aluno em uma atividade intelectual nos afasta do campo das certezas, sendo preciso levar em conta a maneira particular com que cada um se engaja (ou não) nesse processo.

0 curso de letras a que nos referimos prevê em sua grade curricular duas disciplinas específicas em que a escrita acadêmica se faz presente formalmente. Uma no quarto semestre do curso, intitulada Habilidades Integradas em Língua Estrangeira com Ênfase na Escrita e Práticas Discursivas da Academia, sobre a qual fazemos algumas considerações. Nessa disciplina, os alunos devem, de forma muito prática, dedicar-se à escrita acadêmica em língua estrangeira, incluindo aí a escrita de resumos, relatos de pesquisa, resenhas, assim como a participação em atividades acadêmico-orais, tais como a apresentação de comunicações, participação em mesas-redondas, anotações de itens em conferências, dentre outras atividades.

Analisemos, pois, as dificuldades/impasses de uma aluna para produzir uma resenha, em língua estrangeira, que nos parece ilustrativo daquilo que argumentamos sobre a complexidade do processo de entrada nos modos de dizer do discurso acadêmico no espaço discursivo desse curso de letras, um dos lugares privilegiados da formação.

0 relato sobre esses impasses foi obtido a partir de sessões de orientações ocorridas entre o professor formador e a aluna, o que foi registrado, informalmente, pelo professor formador sob a forma de notas de campo que possibilitaram este relato.

\section{A escrita de uma resenha acadêmica: história de um percurso}

A aluna, em questão, deveria escrever uma resenha seguindo as orientações dadas pelo professor ${ }^{4}$. A partir de um assunto escolhido

\footnotetext{
${ }^{4}$ A aluna teve contato com materiais sobre a produção textual na universidade, integrantes da disciplina, os quais forma discutidos em aulas e em sessões individuais de orientação. Dentre os materiais utilizados, destacamos o livro de Motta Roth e Hendges (1989) Produção Textual na Universidade. De forma contextualizada, esse livro procura mostrar as características fundamentais da escrita de gêneros acadêmicos.
} 
pela aluna, ela deveria escrever em língua inglesa a resenha de um texto que dialogasse com um ou mais textos, procurando, dessa forma, ir além das descrições dos conteúdos de ambos os textos, posicionandose frente ao assunto. Essas foram as instruções gerais do trabalho de resenha solicitado, tendo em vista que o professor havia trabalhado com explicações e exemplos de vários tipos de resenha de textos acadêmicos, mostrando a sua função para o trabalho acadêmico. Nesse sentido, o professor enfatizou que o gênero resenha deveria conter minimamente quatro partes: uma introdução do assunto, uma descrição da perspectiva sob a qual o autor desenvolveu aquele determinado tema, uma apreciação do resenhista mediante suas opções teóricas e, finalmente, uma avaliação crítica do trabalho apreciado em que houvesse uma recomendação ou não do texto resenhado aos leitores.

Ressaltamos que a escrita dessa resenha está inserida dentro do conteúdo programático das disciplinas aludidas anteriormente (Habilidades Integradas em Língua Estrangeira com Ênfase na Escrita e Práticas Discursivas da Academia). Em outras palavras, houve um trabalho de preparação sobre esse gênero de escrita solicitado e trabalhado com os alunos previamente.

Passemos, agora, ao relato das dificuldades/impasses vivenciados pela aluna nesse processo de escrita da resenha solicitada na disciplina.

Como o tema deveria ser escolhido pela aluna, um primeiro conflito se apresentou, relativo ao tema a ser escolhido, uma vez que, para isso, seria preciso que ela, a aluna, estivesse identificada com os próprios temas tratados em seu curso de letras, locus de sua formação acadêmico-profissional. Referimo-nos, aqui, a algo que dela o dissesse, que lhe interessasse.

Essa fase do trabalho de escrita da aluna remete-nos a uma realidade dos cursos de letras em que, via de regra, acontece com muita frequência. Há alunos que parecem não se identificar com o curso, apesar de afirmarem, por vezes, que gostam, por exemplo, das línguas que estudam ou mesmo que entraram no curso para aprender a língua inglesa. 0 que ocorre, no entanto, é que esses dizeres nem sempre são sustentados, o que pode ser constatado ao serem perguntados, por exemplo, quanto tempo se dedicam aos estudos dessa língua em seu cotidiano ou mesmo quais os investimentos feitos em materiais didáticos tais como gramáticas, dicionários e tantos outros que, potencialmente, demonstrariam que essa língua e, portanto, a sua aprendizagem, ocupa um lugar concreto de interesse na 
agenda de tarefas desses alunos que seria própria daqueles que estudam uma língua estrangeira, condição sem a qual essa aprendizagem poderia estar fadada ao fracasso.

Em geral, as respostas a essas perguntas são evasivas e demonstram que nem sempre aprender essa língua estrangeira não é algo que está incluído na ordem do desejo desses alunos. ${ }^{5}$

Muitos alunos são, assim, constituídos por um imaginário que lhes permite construir concepções sobre aprender uma língua estrangeira que advém de várias instâncias da sociedade e que reforçam a ideia de que aprender uma língua estrangeira seria algo fácil, sem exigências significativas dos aprendizes. Não se coloca, nessa equação, portanto, que se trata, justamente do contrário: a aprendizagem de uma língua demanda muito psiquicamente de alguém que se lança, ou melhor dizendo, que se impõe o desafio de aprender e se tornar professor de uma determinada língua estrangeira. ${ }^{6}$

A escolha do tema, ainda, proporciona, uma outra dimensão desse conflito que podemos tratar da seguinte forma. Como vimos argumentando, ler e escrever no espaço discursivo-acadêmico não se equivale a ler e a escrever qualquer coisa. A escolha de um tema para a escrita de uma

\footnotetext{
${ }^{5}$ Sobre o desejo de aprender uma língua estrangeira, Prasse (1997, p.73) trabalha com a hipótese, segundo a qual "o desejo de aprender, de saber falar uma língua, se alimenta de duas fontes aparentes que, no fundo, não passam de uma só: inveja dos bens e da maneira como gozam os outros, e inquietação de não estar no lugar necessário, de não poder encontrar seu próprio lugar na língua materna, uma interdição necessária para situar o desejo (o que pode se exprimir como uma inibição para falar ou escrever, por exemplo) (...) o desejo de aprender uma língua estrangeira (é claro, não falo da necessidade constituída por circunstâncias exteriores, como a emigração, por exemplo) pode ser um desejo de ter escolha, de poder escolher a lei, as regras e muitas vezes o mestre de nosso gozo. É o desejo de ser livre para escolher uma ordem na qual "se exprimir", de impor-se a uma ordem por um ato voluntário, aprender, enfim, como se deve falar corretamente e gozar com isso." A reflexão de Prasse parece-nos importante porque não raro vemos alunos em cursos de letras em cuja relação com as línguas estrangeiras que estudam não é possível identificar essa dimensão do desejo e do gozo de que nos fala autora. Em decorrência, a relação desses alunos com o saber específico da língua estrangeira que estudam não parece ser uma relação de constituição nessa língua, mas sim aquela em que a língua permanece como objeto a ser adquirido racionalmente.

${ }^{6}$ Sobre a demanda psíquica requerida de alguém que se dispõe a aprender uma língua estrangeira e,em nosso caso, tornar-se professor dessa língua, o artigo de Revuz (2006) é elucidativo. A autora discute a questão, trabalhando com a idéia de que "aprender uma língua estrangeira é sempre, um pouco, tornar-se um outro” (p.227).
} 
resenha demanda que o aluno se constitua pela via de dizeres que encerram discursos específicos. Em outras palavras, ler e escrever, no espaço discursivo-acadêmico, implica posicionar-se a partir de um lugar teórico com o qual se identifica. Isso é altamente complexo porque está em jogo perceber que esse engajamento em modos de dizer diferentes exige distinguir, necessariamente, as teorias umas das outras. Trata-se, a nosso ver, de uma oportunidade que os alunos têm de experimentar que as diversas teorias sobre o ensino e a aprendizagem de línguas não constituem o objeto de estudo da mesma forma. Eis aí a complexidade do processo que precisa ser vivido/experimentado.

No caso que trazemos, aqui, a aluna escolheu um tema com o qual parecia se identificar, o ensino de língua portuguesa como língua estrangeira, dado que ela estava à época engajada com o mesmo tema para a realização de um curso para alunos estrangeiros, registrados em programas de intercâmbio, em sua universidade.

A escrita do texto propriamente dito provocou o enfrentamentoestranhamento com esse outro modo de dizer específico. 0 primeiro desafio da aluna foi enfrentar o fato de que seu texto estava muito próximo do texto primeiro, ou seja, ela, em suas orientações com o professor formador, sempre ouvia a sua recomendação de que, mesmo se tratando de uma resenha, deveria haver um limite de reprodução e/ou descrição do texto primeiro, sob pena de não ser possível que sua posição de resenhista fosse exercida e ela pudesse se responsabilizar por aquele texto específico denominado resenha. Esse enfrentamento-estranhamento, tal qual administrado pelo professor formador, fez surgir para a aluna uma possibilidade de entender que deveria haver um equilíbrio nas descrições exigidas pelo texto de uma resenha.

Diante desse primeiro impasse, o professor formador não perdeu a chance de adentrar um pouco mais no texto da aluna, discutindo, agora, o lugar da reprodução quando se escreve um texto acadêmico. Argumentou o professor que, de certa forma, a aluna parecia se "colar" no autor do texto resenhado sem conseguir dizer com suas palavras o seu conteúdo. No entanto, esse comentário do professor não se impôs como sendo da ordem de uma moral, de uma censura que usaria isso para julgar de forma implacável o texto da aluna. Ao contrário, o comentário do professor direcionou-se no sentido de dizer que se tratava de uma fase da produção dos trabalhos acadêmicos pela qual aqueles que estão em processo de entrada 
nesses novos modos de dizer passam. Esse é um dos pontos fundamentais que podem marcar uma diferença no trabalho com a escrita acadêmica de um professor formador para um aluno em formação.

Outros problemas na escrita da resenha foram surgindo na medida em que a tarefa de escrevê-la se apresentava. A aluna, ao iniciar o seu texto, não anunciava o tema da resenha, não informando ao leitor sobre qual seria o texto primeiro com o qual estava dialogando, o que comprometia a clareza de seu texto, uma das condições para se atender ao que se quer ao escrever uma resenha.

Ao longo do texto, não havia nenhuma referência ao autor que estava sendo resenhado, assim como a ausência de citações e de referências de acordo com as normas vigentes para a escrita de um texto acadêmico. Havia, ainda, problemas de formatação do texto, o que pôde ser percebido pelo uso equivocado, por exemplo, do parágrafo americano.

0 registro de uso da língua inglesa estava fora dos padrões de formalidade exigidos por um texto acadêmico com marcas de um modo de dizer ainda muito próximo ao da Língua Portuguesa. Esse fato trouxe à tona a natureza da relação do aluno com a língua estrangeira (inglesa), qual seja, uma relação, notadamente, atravessada pela língua materna como um suporte para se estar no espaço discursivo da língua estrangeira. Em outras palavras, a aluna não podia, naquele momento, levar em conta que os modos de dizer algo em uma língua sofrem modificações, por vezes significativas, em uma outra.

Destacamos, nesse momento, que não se trata de apontar defeitos em um trabalho dessa natureza, mas o que mostramos aí são as evidências de como esses detalhes da escrita acadêmica propriamente dita aparecem e devem ser tratados numa perspectiva processual sem que caiamos naquelas máximas, que tanto ouvimos na universidade e em outros ambientes educacionais: ah os alunos não sabem escrever. É nesse sentido que vemos que o trabalho de escrita acadêmica deve ser visto na perspectiva de Riolfi (2003, p.47) quando afirma que se trata de um trabalho de escrita, com a escrita. 0 trabalho de escrita, assim entendido, pode fazer com que aquele que escreve sofra modificações ao voltar ao seu próprio texto, impondo-se a necessidade de (re)escrevê-lo. Essa volta ao próprio texto pode, assim, possibilitar modificações em quem escreve. De acordo com a autora: 
A - É o sujeito quem trabalha efetuando deliberadamente diversas operações discursivas para a construção de uma ficcionalização através da qual o processo de construção do texto escrito fica escondido e velado para o leitor. B - É a escrita quem, uma vez depositada grosseiramente no suporte, trabalha no sujeito, fazendo com que ele mude de posição com relação ao próprio texto e possa, sobre ele, exercer um trabalho.

Para que isso aconteça, a intervenção de um professor, constituído em modos de dizer acadêmicos, pode ajudar um aluno a ver que ele também pode nesses modos se constituir, uma vez que por eles pode ser afetado.

Um outro impasse da aluna nesse processo de escrita da resenha foi a percepção de que havia uma limitação em fazer uma escolha teórica. Contemos o fato: uma das observações feitas pelo professor sobre a resenha escrita pela aluna referiu-se a sua escolha teórica face ao que o artigo preconizava sobre o tema: Ensino de língua portuguesa como língua estrangeira. Ao ser questionada, então, pelo professor, sobre sua concordância com a postura sobre o artigo frente ao tema em estudo, a aluna limitou-se a dar opiniões marcadamente impressionistas, tais como, "acho isso ou aquilo" e aí, quando questionada sobre o fato de que seus argumentos se constituíam em opiniões vagas sobre o assunto, em nível do senso comum,surgiu a necessidade de dizer que em uma resenha, ao nos reportarmos de forma crítica a uma postura teórica usada em um artigo, nós assim o fazemos reconhecendo ou não os méritos de uma teoria, ao mesmo tempo em que nos posicionamos frente ao assunto tratado, também por um viés teórico com o qual nos identificamos. Essa foi a condição mínima apresentada à aluna como ponto de partida para que uma posição sua pudesse ser sustentada em seu texto.

De modo específico, a aluna deparou-se com o fato de que o artigo escolhido para a resenha discutia o assunto valendo-se de uma abordagem de ensino comunicativa, o que implicava determinadas concepções sobre o que seria a língua, a linguagem, o ensinar e o aprender que não constituíam, para ela, pontos pacíficos. Em uma outra disciplina que cursava, Linguística Aplicada, as abordagens de ensino de línguas estrangeiras estavam em discussão e, segundo ela, havia divergências entre uma abordagem e outra.

A aluna foi tocada, assim, pelo fato de que ela deveria ler a aprofundar sobre as outras abordagens sobre o ensino de línguas estrangeiras; 
percebeu que não seria suficiente apenas um artigo sobre o assunto para que ela se posicionasse e pudesse, de alguma forma, sustentar uma posição frente ao artigo lido. Em uma palavra, a aluna se deparou com a falta que gera perguntas para as quais só podemos ter respostas provisórias que nos fazem confrontar posições diferentes. Ela tinha dúvidas sobre o alcance das abordagens sobre o ensino e a aprendizagem de línguas que, por um bom tempo, se apresentavam como um não sentido que, por mais que se tentasse contornar, mais se impunha a necessidade de a ele dar respostas, ainda que provisórias, conforme aludimos anteriormente. Ela se sentiu, a nosso ver, convocada a responder a uma questão acadêmica.

E, diante disso, a aluna foi ao encontro de outros artigos, outras leituras. Posicionou-se, ainda, a aluna diferentemente frente ao curso de Linguística Aplicada que ela também estava cursando à época da escrita da resenha. Notamos que essa falta, nesse caso teórica, vivenciada pela aluna, passou a ser encarada com outros olhares ao se dar conta de que a disciplina Linguística Aplicada estava justamente problematizando algo que era de fundamental importância para sua discussão sobre o ensino e a aprendizagem de português como língua estrangeira.

Em outras palavras, parece ter havido aí uma possibilidade de deslocamento de uma posição discursiva não implicada com as questões afeitas, próprias à sua formação, para uma outra que, por se caracterizar por uma implicação, abriu para a possibilidade de dificuldades relativas à formação e, em decorrência, à entrada na ordem do discurso acadêmico naquilo que concerne à escrita acadêmica em língua estrangeira.

Esse foi o primeiro indício de que a atividade, no caso dessa aluna especificamente, deixou de ser meramente uma atividade escolar para se configurar em algo que pudesse ajudá-la a entrar na ordem do discurso acadêmico, o que, por sua vez, abriu a possibilidade de que ele experimentasse uma escrita acadêmica singular, algo de si estaria ali presente e, em decorrência, uma responsabilidade enunciativa, já que igualmente se abriu a possibilidade de, por sua palavra, se responsabilizar.

E isso está desprovido de um compromisso prévio com qualquer conteúdo, entenda-se, aqui, coerção a uma escolha teórica x ou y, o que comumente vemos acontecer nos cursos de letras, atualmente. Por vezes, o professor formador insistiu no fato de que, naquele momento, não era a sua posição teórica que estava em jogo, mas sim a oportunidade de a aluna levar a termo seu processo de distinção de abordagens teóricas que lhe 
possibilitaria, potencialmente, fazer distinções entre as várias abordagens possíveis sobre o tema de sua resenha.

\section{Considerações finais}

0 percurso dessa aluna, descrito, aqui, possibilita-nos pensar que esse processo de entrada da aluna na ordem do discurso acadêmico, no que diz respeito à escrita, deve ser pensado em sua relação com o professor formador.

Isso porque nesse percurso de escrita de uma resenha acadêmica parece haver um encontro com o não sentido. Mesmo tendo sido faladas e trabalhadas as características de escrita de uma resenha, a aluna, em um primeiro momento, não conseguiu fazer sentido do que precisava fazer para realizar a tarefa de escrever. Deparou-se, assim, com uma diferença radical entre o seu modo de dizer e aquele que lhe era solicitado.

Viveu, desse modo, um confronto que, nesse caso, é constitutivo do processo. Angustiou-se, colocando o corpo em jogo nessa entrada, o que foi visto por sua expressão carregada a cada momento em que o professor acusava alguma impropriedade em seu texto que não condizia com as expectativas de escrita de uma resenha acadêmica.

Énesse sentido que julgamos que a relação com o professor formador pode ser fundamental para algum êxito que se pretenda nesse processo, uma vez que ele pode mediar a tensão produzida entre os modos de dizer da aluna e aqueles que o discurso acadêmico impõe, possibilitando que as dificuldades/impasses vividos pelos alunos, característicos da entrada na ordem do discurso acadêmico, possam ter um destino produtivo.

Isso pôde ser notado, inicialmente, porque o professor se ocupou da aluna provocando-a e, em decorrência, fazendo-a ver seus limites. Notemos que é o professor quem aponta as falhas da escrita da aluna, é ele quem aponta a pertinência ou não da escrita, ou seja, ele funciona como alguém que exerce a autoridade de professor. Ele, assim o faz, porque está constituído desse modo de dizer acadêmico, o que possibilita a aluna também nele se constituir, se dizer.

Ao assumir essa posição de implicação frente a aluna e sua formação, o professor não tinha a priori a garantia de que a aluna reconhecesse nele uma figura de autoridade em quem pudesse se mirar e seguir adiante com sua empreitada específica rumo à escrita de sua resenha. Ela, porém, não 
o faz. Enfrenta a situação e escreve a sua resenha. 0 contrário também poderia ter ocorrido. Isso quer dizer que a aluna reconheceu no professor um sujeito suposto saber, aquele em quem pôde depositar confiança porque, de alguma forma, ele saberia o que seria a sua necessidade de aprendizagem.

No que concerne ao professor, vemos que essa operação só se tornou possível porque a aluna está na ordem do seu desejo. Fazer com que a aluna pudesse experimentar o que é escrever uma resenha acadêmica foi algo sobre o qual valeu a pena trabalhar, valeu a pena debruçar-se. Esse é um aspecto sobre o qual teríamos inúmeros exemplos de professores para quem essa tarefa nunca se impôs e, talvez, nunca se imporá.

Nesse caso específico, o professor se ocupou dessa aluna fazendo com que uma tensão, conforme aludimos anteriormente, fosse produzida entre aquilo que constituía os seus modos de dizer e aquilo que constitui os modos de dizer de uma resenha. Para isso, foi preciso enfrentar seus limites, os impasses enfrentados a cada momento da escrita.

A atuação do professor se faz relevante nesse processo porque, ao tomar a palavra e endereçá-la à aluna, ele o faz a partir das exigências que a entrada na ordem do discurso acadêmico demanda do universitário. Sustenta, assim, sua posição discursivo-enunciativa, possibilitando que a aluna entre no jogo discursivo da demanda específica da escrita acadêmica. Essa entrada só se torna possível porque ao sustentar sua palavra, o professor faz com que aquilo que é da ordem da falta, se imponha à aluna como condição para se enfrentar essa entrada.

Essa tomada da palavra pelo sujeito que, a partir de uma posição discursivo-enunciativa, pode sustentar aquilo que é da ordem de seu desejo, remete-nos à máxima lacaniana, segundo a qual "pela nossa posição de sujeito, somos todos sempre responsáveis" (Lacan, 1998, p.873).

A angústia lacaniana é uma angústia produtora - produz o objetocausa. É o motor da análise e cabe ao analista manejar sua rotação. "O analista é um radar de angústia”, diz Forbes. Com efeito, Lacan a toma como termômetro a ser utilizado pelos psicanalistas: "Sentir o que o sujeito pode suportar de angústia os põe à prova a todo instante" (Lacan, 2005, p.13) A angústia é um parâmetro da direção do tratamento. A experiência analítica é minha referência essencial (idem, p.25). O Seminário X, de Lacan, mantém sua atualidade em relação ao desbussolamento do homem contemporâneo. Viver no mundo globalizado é saber viver com a angústia. Passa-se a uma clínica além da castração, uma clínica voltada a suportar 
a qualidade, o melhor de mim, que não pode se inscrever na civilização, já que esta pasteuriza. Uma clínica sem necessidade da compreensão (Forbes, 2005). Ao não revestir a perda e promover a invenção, a psicanálise é constitutiva de uma ética para nosso tempo.

\section{Referências}

FOUCAULT, M. A ordem do discurso. Trad. de Laura Fraga de Almeida Sampaio. São Paulo, Edições Loyola, 1971.

GEE, J. P. Social linguistics and literacies - ideology in discourses. London, Routledge, 2012.

LACAN, J. A ciência e a verdade. Em Escritos. Rio de Janeiro, Jorge Zahar, 1998.

MOTTA-ROTH e HENDGES. Produção textual na universidade. São Paulo, parábola, 2010.

NASIO, J. D. Lições sobre os 7 conceitos cruciais da psicanálise. Rio de Janeiro, Jorge Zahar, 1989.

PRASSE, J. O desejo das línguas estrangeiras. Revista Internacional, v.1, n.1. Rio de Janeiro, Paris, Nova York, Buenos Aires, 1997.

REVUZ, C. A Língua estrangeira entre o desejo de um outro lugar e o risco do exílio. Trad. de S. Serrani-Infante. Em SIGNORINI (org.) Língua(gem) e Identidade. Campinas: Mercado de Letras, 2006.

RIOLFI, C. Ensinar a escrever: considerações sobre a especificidade do trabalho da escrita. Em Leitura: Teoria e Prática - Associação de Leitura do Brasil, v.21, n.340, Campinas, 2003. 